\title{
openheart Impact of pulmonary hypertension on outcome in patients with moderate or severe tricuspid regurgitation
}

\author{
Sahrai Saeed (1) , ${ }^{1,2}$ Jenna Smith, ${ }^{2}$ Karine Grigoryan, ${ }^{2}$ Stig Urheim, ${ }^{1}$ \\ John B Chambers (D) ,2 Ronak Rajani ${ }^{2}$
}

To cite: Saeed S, Smith J, Grigoryan $\mathrm{K}$, et al. Impact of pulmonary hypertension on outcome in patients with moderate or severe tricuspid regurgitation. Open Heart 2019;6:e001104. doi:10.1136/ openhrt-2019-001104

Received 31 May 2019

Revised 9 July 2019

Accepted 11 September 2019

Check for updates

\section{(C) Author(s) (or their} employer(s)) 2019. Re-use permitted under CC BY-NC. No commercial re-use. See rights and permissions. Published by BMJ.

${ }^{1}$ Department of Heart Disease, Haukeland Universitetssjukehus, Bergen, Norway

${ }^{2}$ Cardiothoracic Centre, Guy's and St Thomas' NHS Foundation Trust, London, UK

\section{Correspondence to}

Dr Sahrai Saeed; sahrai.saeed@ helse-bergen.no

\begin{abstract}
Objectives The true prevalence and disease burden of moderate or severe (significant) tricuspid regurgitation (TR) in patients undergoing routine echocardiography remains unknown. Our aim was to explore the prevalence of significant TR and the impact of pulmonary hypertension (PH) on outcome in a less selected cohort of patients referred to echocardiography.

Methods From 12791 echocardiograms performed between January and December 2010, a total of 209 (1.6\%) patients $(72 \pm 14$ years, $56 \%$ men) were identified with significant TR; $123(0.96 \%)$ with moderate and 86 (0.67\%) with severe TR. Median follow-up time was 80 months (mean $70 \pm 33$ months). Systolic pulmonary artery pressure was derived from peak velocity of tricuspid regurgitant jet plus the right atrial pressure and considered elevated if $\geq 40 \mathrm{~mm} \mathrm{Hg}(\mathrm{PH})$.

Results During follow-up there were 123 (59\%) deaths with no difference in mortality between moderate and severe TR $(p=0.456)$. The death rates were $93(67 \%)$ in patients with $\mathrm{PH}$ versus $30(42 \%)$ without $\mathrm{PH}(\mathrm{p}<0.001)$. $\mathrm{PH}$ was associated with lower event-free survival in moderate (log-rank, $p<0.001$ ), but not in severe TR (logrank, $p=0.133)$. In a multivariate Cox regression analysis adjusted for age, smoking, coronary artery disease, reduced right ventricle $\mathrm{S}^{\prime}$, lower left ventricular ejection fraction at baseline, right atrium size and mitral valve replacement, $\mathrm{PH}$ remained a significant predictor of allcause mortality (HR 2.22; 95\% Cl 1.41 to $3.47, \mathrm{p}=0.001$ ). Conclusions Moderate or severe TR was found in 1.6\% of patients attending for routine echocardiograms. $\mathrm{PH}$ identified a high-risk subset of patients with moderate TR but not with severe TR.
\end{abstract}

\section{INTRODUCTION}

Tricuspid regurgitation (TR) is a common echocardiographic finding affecting nearly 300000 patients per year in Europe. ${ }^{1}$ Historically, its clinical significance and association with adverse outcome has been underappreciated. ${ }^{2}$ In recent years, however, TR has received increased recognition with studies demonstrating a reduced survival and quality of life for patients with untreated moderate/severe TR. ${ }^{3-6}$ Despite these findings, most prior studies have

\section{Key questions}

What is already known about the subject?

- Tricuspid regurgitation (TR) is a common echocardiographic finding in daily clinical practice. Significant TR (moderate or severe) is associated with reduced survival and quality of life if left untreated.

What does this study add?

- The current study shows the true prevalence of significant TR (1.6\%) in an unselected cohort of patients attending for routine echocardiograms. It also demonstrates a poor 3-year survival rate for both moderate and severe TR which is closely related to the concomitant presence of pulmonary hypertension. Increased mortality is not related to the grade of TR but to elevated systolic pulmonary artery pressure and the coexistence of left-sided heart disease.

How might this impact on clinical practice?

- Only a small proportion of patients with significant TR undergo a corrective intervention on TR (replacement or repair). Data from the present study support the practice of performing a tricuspid valve annuloplasty in all patients having left-sided valvular procedures with more than mild TR, especially if the annulus is dilated.

differed substantially in design and were derived from varying patient cohorts that limits the generalisability of their findings. ${ }^{3-9}$ Furthermore, the association of significant TR and pulmonary hypertension $(\mathrm{PH})$ and their combined impact on prognosis have not been systematically evaluated. Due to its heterogeneous nature and common association with $\mathrm{PH}^{7-9}$ the true prevalence and disease burden of significant TR in patients undergoing routine echocardiography remains uncertain. Thus, the primary aim of the current study was to assess the prevalence and disease burden of moderate or severe TR in patients attending for routine transthoracic echocardiography. The secondary aim was to assess the clinical 
and prognostic impact of $\mathrm{PH}$ in patients with moderate or severe TR over a 5-year follow-up period.

\section{METHODS}

\section{Patient population}

A total of 12791 consecutive transthoracic echocardiograms performed at Guy's and St Thomas' Hospitals between 1 January 2010 and 31 December 2010 were reviewed for moderate or severe TR. All patients $>18$ years were included while patients with adult congenital heart disease involving tricuspid valve (TV) were excluded. Serial echocardiographic data were then collected until 31 December 2015. The time to death or TV surgery was recorded for all patients during a median follow-up period of 80 months (mean $70 \pm 33$ months). No patients were lost to follow-up. The clinical records were reviewed to record cardiovascular disease and risk factors. Hypertension was defined as previously known hypertension, use of antihypertensive medications, or office blood pressure values $>140 / 90 \mathrm{~mm} \mathrm{Hg}$. Hypercholesterolaemia was defined as the use of lipid-lowering drugs.

\section{Transthoracic echocardiography}

Echocardiography was performed with Vingmed system 5, 7, 9 GE Medical, Milwaukee, Wisconsin, USA, and a Philips 'Epiq 7' cardiac ultrasound machines. Left ventricular (LV) ejection fraction (LVEF) was measured by the biplane method of disks ${ }^{10}$ or visual estimates. Right ventricular $(\mathrm{RV})$ dimension and function were measured according to joint European and American guidelines. ${ }^{11}$ The shape and movement of the interventricular septum due to PH or RV dysfunction was visually assessed (figure 1A). Tricuspid annular plane systolic excursion (TAPSE) was typically measured from a zoomed M-mode to ensure best accuracy on M-mode (figure 1B) and peak systolic tissue Doppler velocity was measured at the lateral tricuspid annulus (RV $S^{\prime}$ ) in an apical fourchamber view. ${ }^{11} \mathrm{RV}$ dysfunction was defined as RV $\mathrm{S}^{\prime}$ $<10 \mathrm{~cm} / \mathrm{s}$ or TAPSE $<16 \mathrm{~mm} .{ }^{11}$ The severity of TR was assessed both qualitatively using an integrating approach (mainly colour Doppler flow, figure 1C), and semiquantitatively based on a vena contracta wider than $7 \mathrm{~mm}$ for severe and narrow than $7 \mathrm{~mm}$ for moderate TR in those patients available. ${ }^{12}$ Aortic and mitral regurgitation and stenosis were graded according to prevalent guidelines and qualitatively assessed by colour Doppler flow. ${ }^{12} 13$ Primary TR was defined by the presence of abnormal valve morphology, leaflet damage or prolapse. Secondary TR was defined by normal valve morphology associated with a dilated RV, right atrium (RA) or TV annulus with or without RV dysfunction. Systolic pulmonary artery pressure (SPAP) was derived from the peak velocity of tricuspid regurgitant jet (TR Vmax) by applying the simplified Bernoulli equation $\left(\mathrm{SPAP}=4 \mathrm{v}^{2}+\right.$ estimated RA pressure based on the inspiratory changes in the dimension of inferior vena cava) ${ }^{11}$ (figure 1D). PH was defined as SPAP $\geq 40 \mathrm{~mm} \mathrm{Hg.}{ }^{114}$

\section{Follow-up}

All-cause mortality and the rates of valvular intervention were recorded during follow-up. Deaths were confirmed by reviewing the electronic patient record or a death certificate with 17 February 2019 as the censoring date.

\section{Statistical analyses}

SPSS V.24.0 (IBM) was used for data management and statistical analyses. Continuous variables were presented as mean $\pm \mathrm{SD}$. Comparison between moderate and severe TR groups was done by Student's t-test and $\chi^{2}$ analyses as appropriate. The covariates of $\mathrm{PH}$ were identified in univariate and multivariate logistic regression analyses and reported as OR and $95 \%$ CI. Kaplan-Meier curves were used to calculate event-free survival rates and the difference between groups was tested by log-rank test. Cox proportional hazards models were used to assess the association between $\mathrm{PH}$ and all-cause mortality. All variables with $\mathrm{p}<0.1$ in univariate Cox regression analyses (age, smoking, coronary artery disease, reduced RV $\mathrm{S}^{\prime}, \mathrm{PH}$ at baseline, lower LVEF at baseline, RA area and mitral valve replacement) were included in the multivariate Cox regression model. A p value $<0.05$ was considered to be statistically significant.

\section{RESULTS}

\section{Baseline characteristics of the study population}

After reviewing 12791 clinically indicated transthoracic echocardiograms over a period of 1 year (1 January 2010 to 31 December 2010), a total of $209(1.6 \%)$ patients were identified with moderate TR $(\mathrm{n}=123 ; 0.96 \%)$ or severe TR $(\mathrm{n}=86 ; 0.67 \%)$. The mean age was $72 \pm 14$ years, and $56 \%$ were men and $44 \%$ were women. The TR was primary in only $12(5.7 \%)$ of the 209 patients (moderate in 3 and severe in 9) and secondary in $197(94.3 \%)$ (moderate in 120 and severe in 77). Clinical characteristics and echocardiographic measurements of the RV by severity of TR are presented in table 1.

Patients with severe TR were more likely to have systemic hypertension, greater RV basal diameter and RA area, and a higher prevalence of RA annular dilatation (all $\mathrm{p}<0.05)$. By contrast patients with moderate TR had a higher prevalence of diabetes and lung disease and a higher body mass index (all p<0.05) (table 1). In the total population, $31 \%$ had an implanted electrical device (pacemaker or implantable cardioverter-defibrillator (ICD)), $45 \%$ had a significant left-sided valvular heart disease (VHD) and $23 \%$ had LVEF $<40 \%$ (table 1). Among those with significant left-sided VHD, 52 (55\%) had moderate TR and $42(45 \%)$ had severe TR ( $\mathrm{p}=0.348)$. RA area and RV basal diameter were significantly larger in patients with severe TR compared with moderate TR at baseline (figure 2). RV dysfunction (RV $S^{\prime}<10 \mathrm{~cm} / \mathrm{s}$ or TAPSE $<16 \mathrm{~mm}$ ) was found in $43 \%$, and TAPSE had a strong direct correlation with $\mathrm{RV} \mathrm{S}^{\prime}(\mathrm{r}=0.74, \mathrm{p}<0.001)$, inverse correlation with RA pressure $(\mathrm{r}=-0.27, \mathrm{p}=0.001)$ 

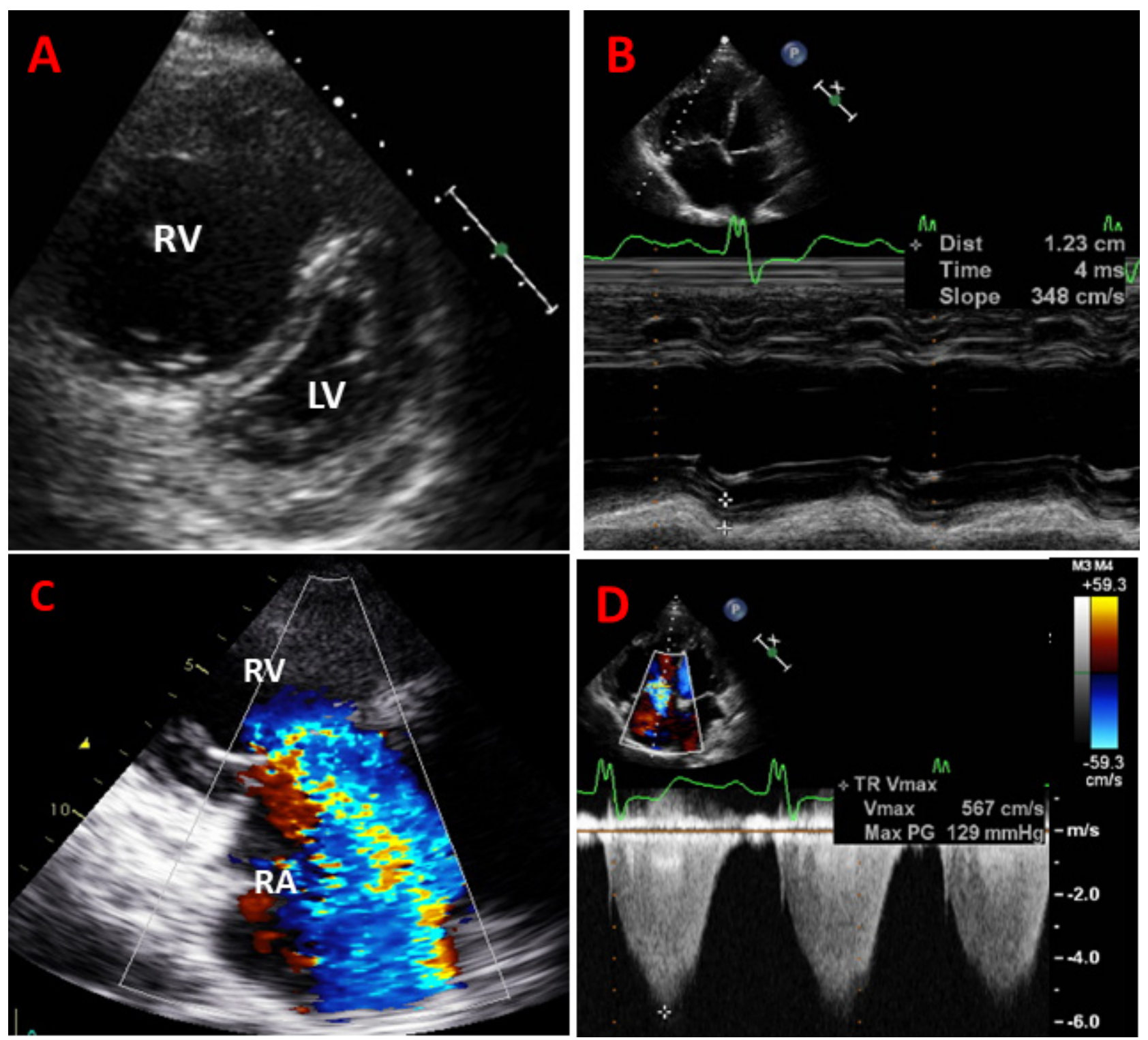

Figure 1 Examples of images obtained from patient with pulmonary hypertension, right ventricular (RV) dilatation and dysfunction and torrential tricuspid regurgitation (TR). (A) Parasternal short-axis view shows severe dilatation of RV and flattened D-shape interventricular septum due to elevated RV pressure; (B) apical four-chamber view shows dilated RV with reduced tricuspid annular plane systolic excursion (TAPSE) of $1.2 \mathrm{~cm}$; (C) torrential TR where colour jet occupies the entire right atrium (RA); and (D) peak velocity of tricuspid regurgitant jet by continuous-wave Doppler with an estimated systolic pulmonary artery pressure of $129 \mathrm{~mm} \mathrm{Hg}$. LV, left ventricle

and a modest positive correlation with LVEF ( $r=0.30$, $\mathrm{p}<0.001)$. LVEF had also a modest positive correlation with $\operatorname{RV~S}^{\prime}(\mathrm{r}=0.36, \mathrm{p}<0.001)$.

\section{PH at baseline}

The prevalence of $\mathrm{PH}$ was $66 \%$ at baseline. There was no difference in the prevalence of $\mathrm{PH}$ in moderate or severe TR $(63 \%$ vs $70 \%, \mathrm{p}=0.340)$ or in patients with or without RV dysfunction ( $73 \%$ vs $61 \%, \mathrm{p}=0.068)$, or left-sided VHD (68\% vs $65 \%, \mathrm{p}=0.596)$. After a multivariable adjustment, reduced RV systolic velocity $\left(\mathrm{S}^{\prime}\right)$ was strongly associated with PH (OR 4.22; 95\% CI 1.37 to $13.05, \mathrm{p}=0.012$ ) (table 2).

\section{Follow-up}

Valvular interventions

During follow-up $78 \%$ of patients were diagnosed with atrial fibrillation. TV interventions were performed in $13(6.2 \%)$ patients, more commonly in those with severe than moderate TR $(11.6 \%$ vs $2.4 \%$; $=0.007)$. TV surgery was performed at the same time as left-sided valve surgery only in six patients with severe TR. Mitral valve replacement occurred in $40(19.2 \%)$ patients $(16.4 \%$ in moderate TR and $23.3 \%$ in severe TR, $\mathrm{p}=0.216$ ) and aortic valve replacement in $45(21.5 \%)$ patients $(23.6 \%$ in moderate TR and $18.6 \%$ in severe TR, $\mathrm{p}=0.389)$. Pulmonary valve replacement was performed only in $3(1.4 \%)$ patients (1 
Table 1 Baseline characteristics of the patients according to the severity of tricuspid regurgitation

\begin{tabular}{|c|c|c|c|c|}
\hline & $\begin{array}{l}\text { Total population } \\
(\mathrm{n}=209)\end{array}$ & Moderate TR $(n=123)$ & $\begin{array}{l}\text { Severe TR } \\
(n=86)\end{array}$ & $P$ value \\
\hline Age (year) & $72 \pm 14$ & $72 \pm 14$ & $72 \pm 14$ & 0.742 \\
\hline Male/female (\%) & $44 / 56$ & $46 / 54$ & $41 / 59$ & 0.419 \\
\hline Height (m) & $1.66 \pm 0.10$ & $1.66 \pm 0.10$ & $1.65 \pm 0.15$ & 0.370 \\
\hline Weight (kg) & $71 \pm 16$ & $74 \pm 17$ & $68 \pm 15$ & 0.015 \\
\hline Body mass index $\left(\mathrm{kg} / \mathrm{m}^{2}\right)$ & $26.0 \pm 5.4$ & $26.7 \pm 5.8$ & $24.8 \pm 4.5$ & 0.028 \\
\hline Systolic blood pressure (mm Hg) & $134 \pm 20$ & $135 \pm 20$ & $132 \pm 20$ & 0.435 \\
\hline Diastolic blood pressure $(\mathrm{mm} \mathrm{Hg})$ & $73 \pm 12$ & $73 \pm 12$ & $72 \pm 12$ & 0.664 \\
\hline Diabetes (\%) & 31 & 38 & 21 & 0.015 \\
\hline Hypertension (\%) & 84 & 80 & 92 & 0.028 \\
\hline Hypercholesterolaemia (\%) & 69 & 71 & 65 & 0.382 \\
\hline Smoking (\%) & 34 & 33 & 34 & 0.919 \\
\hline Coronary artery disease (\%) & 48 & 50 & 46 & 0.602 \\
\hline Overall atrial fibrillation (\%) & 78 & 75 & 82 & 0.250 \\
\hline Chronic lung disease (\%) & 14 & 18 & 8 & 0.042 \\
\hline Pacemaker or ICD at baseline (\%) & 26 & 26 & 26 & 0.983 \\
\hline Overall pacemaker or ICD (\%) & 31 & 31 & 31 & 0.963 \\
\hline Baseline LVEF (\%) & $49 \pm 14$ & $50 \pm 14$ & $50 \pm 14$ & 0.771 \\
\hline Baseline LVEF $\leq 40 \%$ (\%) & 23 & 22 & 26 & 0.542 \\
\hline Baseline TAPSE (mm) & $18.3 \pm 5.5$ & $18.5 \pm 5.0$ & $17.9 \pm 6.0$ & 0.466 \\
\hline $\mathrm{RV}\left(\mathrm{S}^{\prime}\right)(\mathrm{cm} / \mathrm{s})$ & $11.3 \pm 3.4$ & $11.6 \pm 3.5$ & $10.8 \pm 3.2$ & 0.281 \\
\hline RV dysfunction at baseline (\%) & 43 & 41 & 47 & 0.440 \\
\hline RV systolic pressure (mm Hg) & $36 \pm 15$ & $37 \pm 13$ & $36 \pm 17$ & 0.850 \\
\hline Right atrial pressure $(\mathrm{mm} \mathrm{Hg})$ & $11 \pm 6$ & $10 \pm 6$ & $12 \pm 6$ & 0.07 \\
\hline $\operatorname{SPAP}(\mathrm{mm} \mathrm{Hg})$ & $47 \pm 16$ & $47 \pm 16$ & $47 \pm 18$ & 0.873 \\
\hline Pulmonary hypertension (\%) & 66 & 63 & 70 & 0.340 \\
\hline RV basal diameter $(\mathrm{cm})$ & $4.2 \pm 0.6$ & $4.1 \pm 0.5$ & $4.7 \pm 0.6$ & $<0.001$ \\
\hline Right atrium end-systolic area $\left(\mathrm{cm}^{2}\right)$ & $28 \pm 9$ & $27 \pm 8$ & $30 \pm 10$ & 0.002 \\
\hline Right atrium annular dilatation (\%) & 74 & 68 & 83 & 0.020 \\
\hline Vena contracta $(\mathrm{mm})$ & $7.8 \pm 3.2$ & $5.7 \pm 1.4$ & $9.0 \pm 3.2$ & 0.005 \\
\hline Tricuspid valve replacement (\%) & 6.2 & 2.4 & 11.6 & 0.007 \\
\hline Mitral valve replacement (\%) & 19 & 16 & 23 & 0.216 \\
\hline Aortic valve replacement (\%) & 22 & 24 & 19 & 0.389 \\
\hline Significant left-sided VHD (\%) & 45 & 42 & 49 & 0.348 \\
\hline Moderate or severe MR (\%) & 39 & 37 & 43 & 0.348 \\
\hline Moderate or severe MS (\%) & 6 & 7 & 6 & 0.839 \\
\hline Moderate or severe AR (\%) & 6 & 5 & 8 & 0.337 \\
\hline Moderate or severe AS (\%) & 9 & 8 & 9 & 0.766 \\
\hline Mean follow-up (months) & $70 \pm 33$ & $68 \pm 34$ & $71 \pm 32$ & 0.567 \\
\hline Deaths during follow-up (\%) & 59 & 61 & 56 & 0.456 \\
\hline
\end{tabular}

AR, aortic regurgitation; AS, aortic stenosis; ICD, implantable cardioverter-defibrillator; LVEF, left ventricular ejection fraction; MR, mitral regurgitation; MS, mitral stenosis;RV, right ventricle/ventricular;SPAP, systolic pulmonary artery pressure; TAPSE, tricuspid annular plane systolic excursion;TR, tricuspid regurgitation; VHD, valvular heart disease. 


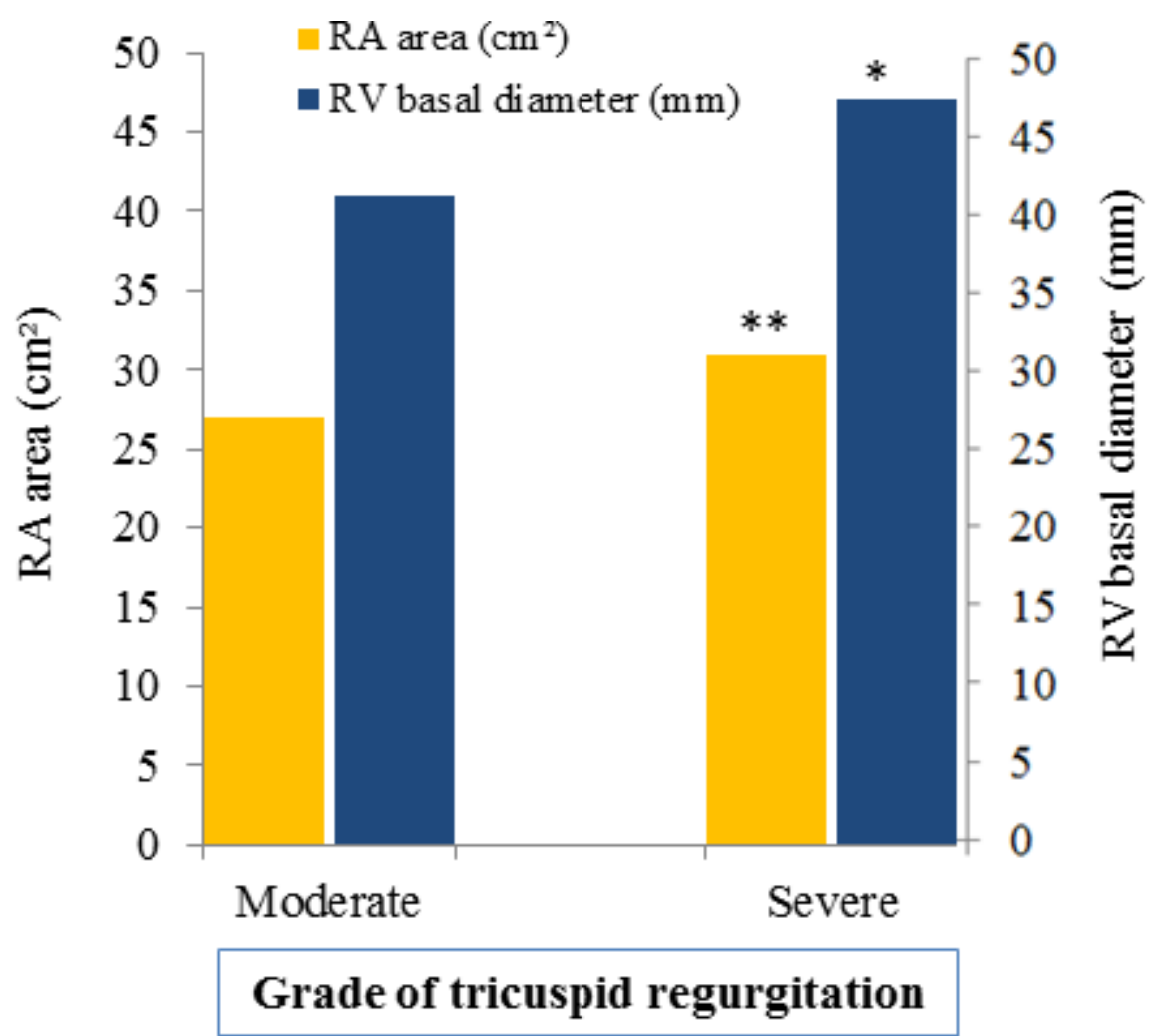

Figure 2 Right atrium (RA) area and right ventricular (RV) basal diameter according to the severity grade of tricuspid regurgitation. ${ }^{*} \mathrm{p}<0.001 ;{ }^{* *} \mathrm{p}<0.01$.

in moderate TR and 2 in severe TR). None of these three patients had congenital heart disease.

\section{Prediction of all-cause mortality}

During a median follow-up of 80 months (mean $70 \pm 33$ months), $123(59 \%)$ patients died. The mortality rate was similar for moderate TR $(\mathrm{n}=75(61 \%)$ and severe TR $(\mathrm{n}=48(56 \%), \mathrm{p}=0.456)$ ) (figure 3A). In patients with moderate TR, the event-free survival was $90 \% \pm 3 \%$ at 1 year, $85 \% \pm 3 \%$ at 2 years, $78 \% \pm 4 \%$ at 3 years and $57 \% \pm 5 \%$ at 6 years. In patients with severe TR, the event-free survival was $95 \% \pm 2 \%$ at 1 year, $89 \% \pm 3 \%$ at 2 years, $79 \% \pm 4 \%$ at 3 years and $57 \% \pm 5 \%$ at 6 years. The death rates were 93 $(67.4 \%)$ in patients with $\mathrm{PH}$ versus $30(42.3 \%)$ in patients with normal SPAP $(p<0.001)$. In the entire study population, patients with $\mathrm{PH}$ had significantly lower eventfree survival rates than those without $\mathrm{PH}$ at $1(89 \pm 3 \%$ vs $99 \pm 1 \%), 2(83 \pm 3 \%$ vs $96 \pm 2 \%), 3(73 \pm 4 \%$ vs $90 \pm 4 \%)$ and 6 years $(47 \pm 4 \%$ vs $76 \pm 5 \%)$ (log-rank, $\mathrm{p}<0.001)$ (figure $3 \mathrm{~B}$ ). When patients were segregated into moderate and severe TR, PH was associated with lower event-free survival in moderate (log-rank, $\mathrm{p}<0.001$ ) (figure $3 \mathrm{C}$ ), but not in severe TR (log-rank, $\mathrm{p}=0.089$ ) (figure 3D). Furthermore, $\mathrm{PH}$ was a predictor of survival irrespective of significant left-sided VHD (log-rank, $\mathrm{p}<0.01)$. The univariate predictors of all-cause mortality are presented in table 3. Atrial fibrillation, RV dysfunction and significant left-sided VHD had no impact on all-cause mortality (table 3).

In a multivariate Cox regression analysis adjusted for age, smoking, coronary artery disease, reduced RV $\mathrm{S}^{\prime}$, lower LVEF at baseline, RA area and mitral valve replacement, $\mathrm{PH}$ at baseline remained a powerful and independent predictor of all-cause mortality (HR 2.22; 95\% CI 1.43 to $3.47, \mathrm{p}=0.001$ ) (table 3 ).

\section{DISCUSSION}

Our study has several important findings. First, the prevalence of significant TR in a less selective cohort of patients attending for a routine transthoracic echocardiogram was $1.6 \%$. Second, these patients had a very high cardiovascular disease burden and an equally poor prognosis with a 3-year survival of $78 \%$ for moderate TR and $79 \%$ for severe TR. Third, survival was most closely related to the presence of likely PH but not to the grade of TR or the presence of significant left-sided VHD.

Previous work shows that the prevalence of TR and its outcome vary according to the nature of the population. Some studies included only isolated TR, ${ }^{7}$ predominantly male patients, ${ }^{4}$ TR associated with implanted electrical devices, ${ }^{1516}$ or only TR from surgical series. ${ }^{17-19}$ By contrast, the current cohort comprised a consecutive group of patients who were referred for echocardiography across the full-spectrum clinical indications. Our population prevalence of $1.6 \%$ was similar to the $2.7 \%$ community prevalence in people aged $>65$ reported in the UK OxVALVE study, ${ }^{20}$ although lower than the $5 \%$ prevalence in an analysis of 79043 patients performed by a private community echocardiography service. ${ }^{21}$ In another recent community-based study by Topilsky et 
Table 2 Univariate and multivariate covariates of pulmonary hypertension at baseline

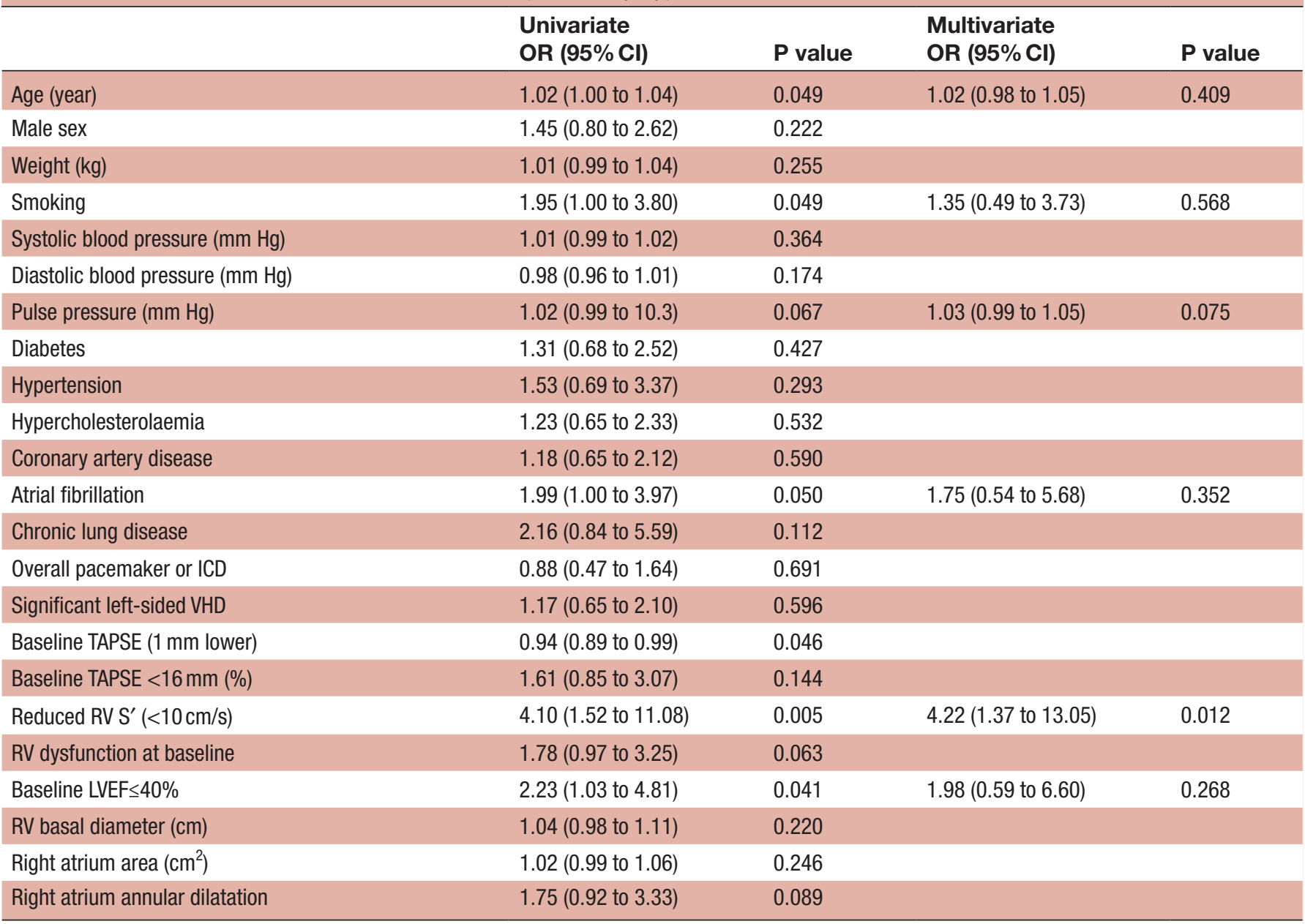

ICD, implantable cardioverter-defibrillator; LVEF, left ventricular ejection fraction;RV, right ventricle/ventricular; TAPSE, tricuspid annular plane systolic excursion; VHD, valvular heart disease.

$a l$, the age and sex-adjusted prevalence of moderate or severe TR was reported as $0.55 \% .^{22}$ Interestingly, large community-based studies of valve disease prevalence in the USA and Norway ${ }^{23} 24$ addressed only left-sided VHD and did not report the prevalence of TR, which our results suggest may have limited their ability to predict outcome.

The presence of significant TR was associated with a 6 -year event-free survival, only $57 \%$ for both moderate and severe TR. However, PH rather than the grade of TR was the most powerful predictor of outcome. The 6 -year event-free survival was $47 \% \pm 4 \%$ for patients with $\mathrm{PH}$ versus $76 \% \pm 5 \%$ without $\mathrm{PH}$, which confirms previous reports. $^{3-6}$

Current European guidelines on VHD consider symptoms or a progressive RV dilatation or dysfunction in the absence of symptoms as indications for surgery in patients with severe primary TR. ${ }^{2}$ Similarly, a liberal approach is recommended for preventive TV repair in patients with even less severe secondary TR undergoing concomitant left-sided heart valve surgery if annular dilatation of TV $\left(\geq 40 \mathrm{~mm}\right.$ or $\left.>21 \mathrm{~mm} / \mathrm{m}^{2}\right)$ is present. ${ }^{2}$ This is particularly important to avoid irreversible RV myocardial damage late after left-sided valve procedures. Nevertheless, in routine clinical practice there is a poor adherence to clinical guidelines with only a small proportion of patients with significant TR undergoing a corrective intervention on TR (replacement or repair). ${ }^{25}$ This was also evident from our study that demonstrates only $6.2 \%(n=13)$ of patients underwent a surgical intervention on TV ( 7 repairs and 6 replacement) versus $19.2 \%$ intervention on mitral and $21.5 \%$ on aortic valve. It is likely that this practice relates to an overestimation of surgical risk, or a perception that the TR is likely to regress following left-sided valvular intervention. In fact, the progressive nature of the disease may cause TV annulus dilatation, impaired RV function and subsequent worsening of TR if left untreated at the time of left-sided valve intervention. ${ }^{26}$ In addition, redo operations often carry a high risk. Furthermore, several studies have demonstrated that TV annuloplasty during surgery for left-sided VHD is associated with improved outcome. ${ }^{26-28}$ Hence, data from the present study as well as previous studies support the practice of performing a TV annuloplasty in all patients having left-sided valvular procedures with anything more than mild TR, especially if the annulus is dilated. ${ }^{21} 22$ 

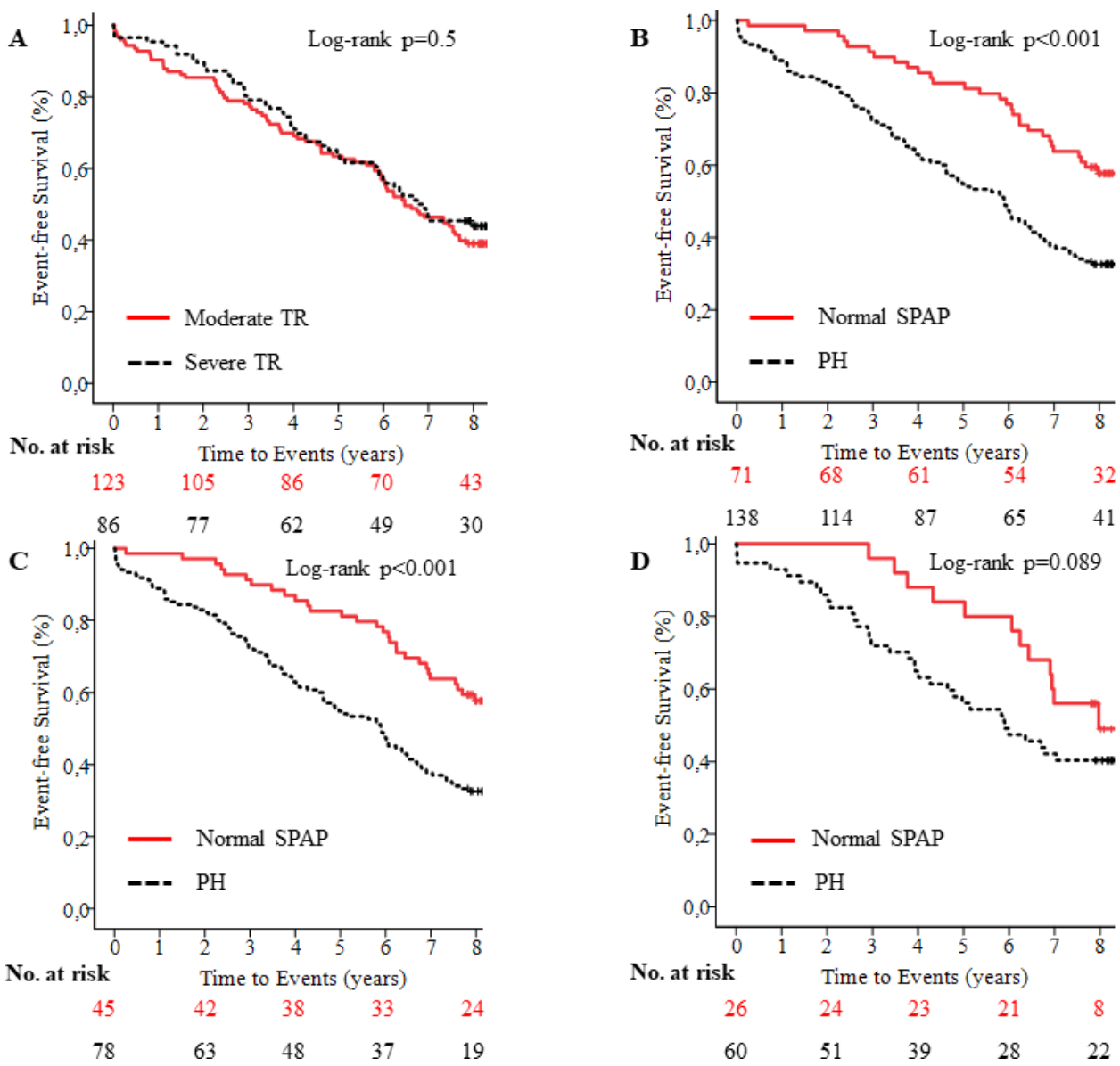

Figure 3 Kaplan-Meier survival curves show event-free survival in patients with moderate and severe tricuspid regurgitation $(\mathrm{A})$, and in patients with pulmonary hypertension $(\mathrm{PH})$ versus patients with normal systolic pulmonary artery pressure (SPAP) at baseline in entire study population (B), patients with moderate $(\mathrm{C})$ and severe tricuspid regurgitation (D). $\mathrm{PH}$, pulmonary hypertention; TR, tricuspid regurgitation.

Moderate or severe TR can be markers of PH or RV dysfunction. Kammerlander et $a l^{29}$ showed that RV dysfunction, but not significant TR, was independently associated with late survival following left-sided heart valve surgery. The authors speculated that impairment of RV function in their patients might be linked to a postcapillary $\mathrm{PH}$ caused by high LV filling pressure in left-sided VHD. The pathophysiological mechanism for significant functional TR caused or aggravated by $\mathrm{PH}$ secondary to left-sided VHD may be due to a sustained $\mathrm{RV}$ pressure overload, RV dilatation and remodelling of the subvalvular apparatus of $\mathrm{TV} \cdot{ }^{29}$ Most studies show that TR grade progression is not closely related to the baseline pulmonary artery (PA) pressure e $^{30} 31$ which agrees with our findings. In a less selected study of patients with TR with predominantly preserved LVEF who were referred to echocardiography, atrial fibrillation and change in SPAP, but not baseline SPAP, predicted TR grade progression. ${ }^{31}$ By contrast Chen $e t a l^{32}$ found a correlation between PH and grade of TR and showed that TR was an independent predictor of survival. In their study, patients with severe TR had a significantly heightened risk of death compared with those who had lesser degrees of TR. We showed that TR Vmax portended poor prognosis in patients with moderate but not severe TR. This may be because in severe TR with significant malcoaptation of TV leaflets, the commonly used Bernoulli equation may underestimate SPAP. ${ }^{11}$ Furthermore, PA pressure may fall as RV dysfunction develops and this may explain why we showed a trend towards prognostic power for RV S', a marker of systolic RV function.

Given the load and pressure-sensitive nature of TV and RV, our study suggests that efforts should be made to decrease pressure overload (elevated pulmonary pressure due to left-sided VHD) and volume overload by optimising the management of heart failure according to contemporary recommendations. Further prospective studies are warranted to explore the additive survival benefit of early TV surgery in less severe TR at the same time as left-sided valve surgery to avoid an irreversible pressure overload-induced myocardial dysfunction.

\section{Limitations}

There are some limitations to our study. First, a quarter of patients had implanted a device (ICD or pacemaker) at baseline. Whether a worsening of TR was induced by device leads remains uncertain. However, having implanted ICD or pacemaker was not associated with 
Table 3 The predictors of all-cause mortality in univariate and multivariate Cox regression analyses

\begin{tabular}{|c|c|c|c|c|}
\hline & $\begin{array}{l}\text { Univariate } \\
\text { HR }(95 \% \text { CI) }\end{array}$ & $P$ value & $\begin{array}{l}\text { Multivariate } \\
\text { HR }(95 \% \text { CI) }\end{array}$ & $P$ value \\
\hline Age (year) & 1.04 (1.03 to 1.06$)$ & $<0.001$ & 1.04 (1.02 to 1.06$)$ & $<0.01$ \\
\hline Male sex & $1.12(0.79$ to 1.60$)$ & 0.528 & & \\
\hline Body mass index $\left(\mathrm{kg} / \mathrm{m}^{2}\right)$ & 1.02 (0.99 to 1.06$)$ & 0.221 & & \\
\hline Smoking & 1.44 (0.99 to 2.10$)$ & 0.054 & 1.21 (0.79 to 1.86$)$ & 0.384 \\
\hline Systolic blood pressure $(\mathrm{mm} \mathrm{Hg})$ & 0.99 (0.98 to 1.01$)$ & 0.313 & & \\
\hline Diabetes & 1.02 (0.68 to 1.51$)$ & 0.933 & & \\
\hline Hypertension & 1.31 (0.76 to 2.26$)$ & 0.325 & & \\
\hline Hypercholesterolaemia & 1.42 (0.93 to 2.15$)$ & 0.103 & & \\
\hline Coronary artery disease & 2.15 (1.49 to 3.10$)$ & $<0.001$ & 1.76 (0.95 to 3.25$)$ & 0.071 \\
\hline Atrial fibrillation & 1.40 (0.87 to 2.24$)$ & 0.165 & & \\
\hline Chronic lung disease & 1.24 (0.76 to 2.03$)$ & 0.384 & & \\
\hline Overall PM or ICD & 1.12 (0.78 to 1.63$)$ & 0.558 & & \\
\hline Significant left-sided VHD & 1.03 (0.72 to 1.48$)$ & 0.865 & & \\
\hline Baseline TAPSE (1 mm lower) & 0.98 (0.95 to 1.02$)$ & 0.410 & & \\
\hline Reduced RV S' & 1.67 (0.98 to 2.89$)$ & 0.059 & 1.42 (0.76 to 2.66$)$ & 0.272 \\
\hline $\mathrm{PH}$ at baseline & 2.22 (1.46 to 3.37 ) & $<0.001$ & 2.22 (1.41 to 3.47 ) & 0.001 \\
\hline Lower LVEF at baseline (\%) & 0.99 (0.98 to 1.00$)$ & 0.027 & 0.98 (0.97 to 0.99$)$ & 0.009 \\
\hline RV dysfunction at baseline & 0.99 (0.69 to 1.42$)$ & 0.966 & & \\
\hline TR grade (severe vs moderate) & 0.88 (0.62 to 1.27$)$ & 0.501 & & \\
\hline RV basal diameter (cm) & 0.98 (0.95 to 1.01$)$ & 0.978 & & \\
\hline Right atrium area $\left(\mathrm{cm}^{2}\right)$ & $1.02(1.00$ to 1.04$)$ & 0.043 & 1.02 (0.99 to 1.04$)$ & 0.078 \\
\hline Mitral valve replacement & 0.51 (0.30 to 0.87$)$ & 0.013 & 0.65 (0.37 to 1.16$)$ & 0.147 \\
\hline Aortic valve replacement & $1.11(0.72$ to 1.71$)$ & 0.648 & & \\
\hline
\end{tabular}

ICD, implantable cardioverter-defibrillator; LVEF, left ventricular ejection fraction; $\mathrm{PH}$, pulmonary hypertension; PM, pacemaker; RV, right ventricle/ventricular; TAPSE, tricuspid annular plane systolic excursion;TR, tricuspid regurgitation; VHD, valvular heart disease.

all-cause mortality. Second, the exact information on functional class, the frequencies of heart failure-related hospitalisations and the types of heart failure medications was unavailable. Hence, we could not assess the impact of TR severity on clinical endpoints such as heart failure-related hospitalisations. Nevertheless, all patients received standard medical care according to the guidelines. Third, the data on diastolic dysfunction were not collected. Fourth, we did not have information about other causes of PH that may have impact on the interpretation of the prognostic data. Fifth, it is possible that the borderline significant association between $\mathrm{PH}$ and all-cause mortality in patients with severe TR represents lack of power rather than absence of true effect on mortality. Finally, mild or trivial TR was excluded from the present study and the lack of a control group of subjects may be considered as a limitation.

\section{CONCLUSION}

Moderate or severe TR is rarely isolated and is commonly associated with left-sided VHD and PH. The prognosis of moderate or severe TR is poor with a high mortality rate observed in patients with moderate TR and PH.

Acknowledgements The authors thank the participants of the present study for their important contributions and the Bergesenstiftelsen for support.

Contributors SS and RR contributed to study design, acquisition, analysis and interpretation of data, writing the article and final approval. JS and KG contributed to acquisition of data and revising the article. SU contributed to interpretation of data and revising the article. JBC contributed to interpretation of data, revising the article for important intellectual content and final approval.

Funding Bergesenstiftelsen provided financial support for SS to conduct this study.

Competing interests None declared.

Patient consent for publication Not required.

Ethics approval The study was approved by the NHS Health Research Authority and the local Institutional Review Board (study protocol ID 260396/2019).

Provenance and peer review Not commissioned; internally peer reviewed.

Data availability statement Data may be obtained from a third party and are not publicly available. All data relevant to the study are included in the article or uploaded as supplementary information.

Open access This is an open access article distributed in accordance with the Creative Commons Attribution Non Commercial (CC BY-NC 4.0) license, which permits others to distribute, remix, adapt, build upon this work non-commercially, and license their derivative works on different terms, provided the original work is 
properly cited, appropriate credit is given, any changes made indicated, and the use is non-commercial. See: http://creativecommons.org/licenses/by-nc/4.0/.

\section{ORCID iDs}

Sahrai Saeed http://orcid.org/0000-0003-4041-5019

John B Chambers http://orcid.org/0000-0002-7169-3786

\section{REFERENCES}

1 Rodés-Cabau J, Taramasso M, O'Gara PT. Diagnosis and treatment of tricuspid valve disease: current and future perspectives. Lancet 2016;388:2431-42.

2 Baumgartner H, Falk V, Bax JJ, et al. Esc scientific document group. 2017 ESC/EACTS guidelines for the management of valvular heart disease. Eur Heart J 2017;38:2739-91.

3 Koelling TM, Aaronson KD, Cody RJ, et al. Prognostic significance of mitral regurgitation and tricuspid regurgitation in patients with left ventricular systolic dysfunction. Am Heart J 2002;144:524-9.

4 Nath J, Foster E, Heidenreich PA. Impact of tricuspid regurgitation on long-term survival. J Am Coll Cardiol 2004;43:405-9.

5 Neuhold S, Huelsmann M, Pernicka E, et al. Impact of tricuspid regurgitation on survival in patients with chronic heart failure: unexpected findings of a long-term observational study. Eur Heart $J$ 2013;34:844-52.

6 Höke U, Auger D, Thijssen J, et al. Significant lead-induced tricuspid regurgitation is associated with poor prognosis at long-term followup. Heart 2014:100:960-8.

7 Topilsky Y, Nkomo VT, Vatury O, et al. Clinical outcome of isolated tricuspid regurgitation. JACC Cardiovasc Imaging 2014;7:1185-94

8 Strange G, Playford D, Stewart S, et al. Pulmonary hypertension: prevalence and mortality in the Armadale echocardiography cohort. Heart 2012;98:1805-11.

9 Medvedofsky D, Aronson D, Gomberg-Maitland M, et al. Tricuspid regurgitation progression and regression in pulmonary arterial hypertension: implications for right ventricular and tricuspid valve apparatus geometry and patients outcome. Eur Heart $J$ Cardiovasc Imaging 2017;18:86-94.

10 Lang RM, Bierig M, Devereux RB, et al. Recommendations for chamber quantification. Eur J Echocardiogr 2006;7:79-108.

11 Rudski LG, Lai WW, Afilalo J, et al. Guidelines for the echocardiographic assessment of the right heart in adults: a report from the American Society of echocardiography endorsed by the European association of echocardiography, a registered branch of the European Society of cardiology, and the Canadian Society of echocardiography. J Am Soc Echocardiogr 2010;23:685-713.

12 Lancellotti P, Tribouilloy C, Hagendorff A, et al. Scientific document Committee of the European association of cardiovascular imaging recommendations for the echocardiographic assessment of native valvular regurgitation: an executive summary from the European association of cardiovascular imaging. Eur Heart $J$ Cardiovasc Imaging 2013;14:611-44.

13 Zoghbi WA, Chambers JB, Dumesnil JG, et al. Echocardiography and Doppler ultrasound: a report from the American Society of Echocardiography's Guidelines and Standards Committee and the Task Force on Prosthetic Valves. J Am Soc Echocardiogr 2009;22:975-1014.

14 Galiè N, Humbert M, Vachiery J-L, et al. 2015 ESC/ERS guidelines for the diagnosis and treatment of pulmonary hypertension: the joint Task force for the diagnosis and treatment of pulmonary hypertension of the European Society of cardiology (ESC) and the European respiratory Society (ERS): endorsed by: association for
European paediatric and congenital cardiology (AEPC), International Society for heart and lung transplantation (ISHLT). Eur Heart $J$ 2016;37:67-119.

15 Taramasso M, Vanermen $\mathrm{H}$, Maisano $\mathrm{F}$, et al. The growing clinical importance of secondary tricuspid regurgitation. J Am Coll Cardiol 2012;59:703-10.

16 Taramasso M, Hahn RT, Alessandrini $\mathrm{H}$, et al. The International Multicenter TriValve Registry: Which Patients Are Undergoing Transcatheter Tricuspid Repair? JACC Cardiovasc Interv 2017;10:1982-90.

17 Mutlak D, Lessick J, Reisner SA, et al. Echocardiography-based spectrum of severe tricuspid regurgitation: the frequency of apparently idiopathic tricuspid regurgitation. J Am Soc Echocardiogr 2007;20:405-8.

18 Staab ME, Nishimura RA, Dearani JA. Isolated tricuspid valve surgery for severe tricuspid regurgitation following prior left heart valve surgery: analysis of outcome in 34 patients. J Heart Valve Dis 1999;8:567-74.

19 Girard SE, Nishimura RA, Warnes CA, et al. Idiopathic annular dilation: a rare cause of isolated severe tricuspid regurgitation. $J$ Heart Valve Dis 2000;9:283-7.

20 d'Arcy JL, Coffey S, Loudon MA, et al. Large-scale community echocardiographic screening reveals a major burden of undiagnosed valvular heart disease in older people: the OxVALVE population cohort study. Eur Heart J 2016;37:3515-22.

21 Marciniak A, Glover K, Sharma R. Cohort profile: prevalence of valvular heart disease in community patients with suspected heart failure in UK. BMJ Open 2017;7:e012240.

22 Topilsky Y, Maltais S, Medina Inojosa J, et al. Burden of Tricuspid Regurgitation in Patients Diagnosed in the Community Setting. JACC Cardiovasc Imaging 2019;12:433-42.

23 Nkomo VT, Gardin JM, Skelton TN, et al. Burden of valvular heart diseases: a population-based study. Lancet 2006;368:1005-11.

24 Lindekleiv H, Løchen M-L, Mathiesen EB, et al. Echocardiographic screening of the general population and long-term survival: a randomized clinical study. JAMA Intern Med 2013;173:1592-8.

25 Stuge O, Liddicoat J. Emerging opportunities for cardiac surgeons within structural heart disease. $J$ Thorac Cardiovasc Surg 2006;132:1258-61.

26 Van de Veire NR, Braun J, Delgado V, et al. Tricuspid annuloplasty prevents right ventricular dilatation and progression of tricuspid regurgitation in patients with tricuspid annular dilatation undergoing mitral valve repair. J Thorac Cardiovasc Surg 2011;141:1431-9.

27 Dreyfus GD, Corbi PJ, Chan KMJ, et al. Secondary tricuspid regurgitation or dilatation: which should be the criteria for surgical repair? Ann Thorac Surg 2005;79:127-32.

28 Benedetto U, Melina G, Angeloni E, et al. Prophylactic tricuspid annuloplasty in patients with dilated tricuspid annulus undergoing mitral valve surgery. J Thorac Cardiovasc Surg 2012;143:632-8.

29 Kammerlander AA, Marzluf BA, Graf A, et al. Right ventricular dysfunction, but not tricuspid regurgitation, is associated with outcome late after left heart valve procedure. J Am Coll Cardiol 2014:64:2633-42.

30 Mutlak D, Aronson D, Lessick J, et al. Functional tricuspid regurgitation in patients with pulmonary hypertension: is pulmonary artery pressure the only determinant of regurgitation severity? Chest 2009;135:115-21.

31 Shiran A, Najjar R, Adawi S, et al. Risk factors for progression of functional tricuspid regurgitation. Am J Cardiol 2014;113:995-1000.

32 Chen L, Larsen CM, Le RJ, et al. The prognostic significance of tricuspid valve regurgitation in pulmonary arterial hypertension. Clin Respir J 2018;12:1572-80. 